\title{
Left main coronary artery compression by the right pulmonary artery in a patient with congenital pulmonic stenosis
}

\section{Compresión del tronco coronario izquierdo por la arteria pulmonar derecha en un paciente con estenosis pulmonar congénita}

\author{
Eduardo Bahena-López* and Jorge Loya-Centurión \\ Department of Cardiology, Instituto Nacional de Cardiología Ignacio Chávez, Mexico City, Mexico
}

\begin{abstract}
Congenital pulmonary stenosis (PS) can be associated with pulmonary artery (PA) dilatation. In some cases, this can cause compression of nearby structures including the left main coronary artery (LMCA). This compression causes angina and is considered an indication for surgical treatment. We present the case of a patient with PS and angina secondary to LMCA compression by the right PA and review the main indications and options for surgical treatment.
\end{abstract}

Key words: Left main coronary artery. Pulmonary stenosis. Pulmonary artery. Angina. Mexico.

\section{Resumen}

La estenosis pulmonar congénita se asocia a dilatación de la arteria pulmonar. En algunos casos esto puede causar compresión de las estructuras adyacentes incluyendo el tronco de la coronaria izquierda. Esta compresión causa angina y es considerada una indicación para tratamiento quirúrgico. Presentamos el caso de un paciente con estenosis pulmonar y angina secundaria a compresión del tronco de la coronaria izquierda por la arteria pulmonar derecha y revisamos las indicaciones y opciones de tratamiento quirúrgico.

Palabras clave: Tronco coronaria izquierda. Estenosis pulmonar. Arteria pulmonar. Angina. México.

\section{Introducción}

A 52-year-old man presented with a history of ventricular septal defect (VSD) and congenital pulmonary valve stenosis (pulmonary stenosis [PS]) who underwent pulmonary valve replacement with a biologic valve at 15 years old and VSD closure with pericardial patch at 17 years old in another institution. The indication and specifics of each procedure are unknown.

$\mathrm{He}$ had a 2-year history of stable angina (Class II of the Canadian Cardiovascular Society). An echocardiogram was performed which reported reopening of the VSD. He was referred to our institute for workup. During workup a transthoracic echocardiogram was performed, license (http://creativecommons.org/licenses/by-nc-nd/4.0/).

Available online: $30-01-2020$ Arch Cardiol Mex (Eng). 2020;90(1):56-58 www.archivoscardiologia.com 


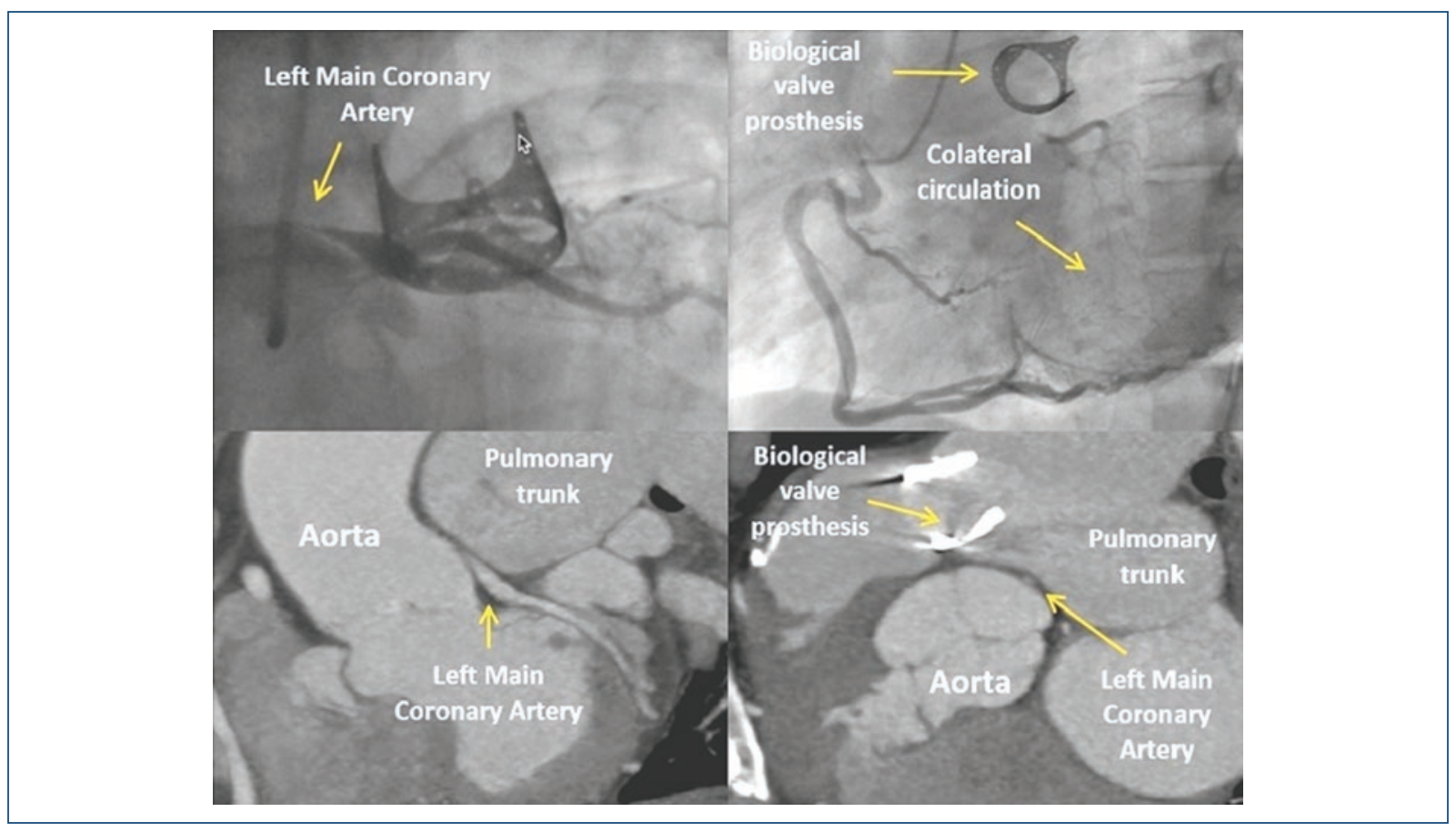

Figure 1. Extrinsic left main coronary artery (LMCA) compression of $90 \%$ and reduced blood flow to the left anterior descending with collateral circulation form de RCA in coronary angiography. LMCA compression by the pulmonary artery in computed tomography.

showing reduced right ventricular systolic function, left ventricle with anterior wall and septal hypokinesia and an ejection fraction of $45 \%$, reopened VSD with leftright shunt and a dysfunctional prosthetic pulmonary valve (PPV) due to severe stenosis and severe regurgitation. A computed tomography showed obstruction of the left main coronary artery (LMCA) due to extrinsic compression by the right PA (RPA), left anterior descending ( $L A D)$, and left circumflex arteries where filled by collateral circulation, dilation of MPA, and its branches (MPA $52 \mathrm{~mm}$, RPA $53 \mathrm{~mm}$, and left PA $44 \mathrm{~mm}$ ); VSD with a $17 \times 14 \mathrm{~mm}$ diameter (Fig. 1). A right and left cardiac catheterization was performed which showed extrinsic LMCA compression with $90 \%$ stenosis and reduced blood flow to the LAD, PPV with a $60 \mathrm{mmHg}$ gradient, and VSD with left-right shunt, mean pulmonary pressure of $20 \mathrm{mmHg}$ and a Qp: Qs ratio of 1.2 .

The patient was admitted for surgical treatment. He underwent pulmonary valve replacement with a prosthetic biological valve and RPA plasty. Coronary artery bypass of the LAD was attempted, but the artery could not be visualized during the procedure, so revascularization to the obtuse marginal artery with a radial artery graft was performed. The total surgical time was $11 \mathrm{~h}$, with $361 \mathrm{~min}$ of extracorporeal circulation and aortic cross-clamping of $219 \mathrm{~min}$. The patient was admitted to the post-operative intensive therapy with cardiogenic shock. He had a torpid evolution persisting in cardiogenic shock despite the use of vasopressin, norepinephrine, and dobutamine, eventually presenting multiple organ failure and 4 days after surgical procedure presented asystole and was declared dead after failure of advanced cardiopulmonary resuscitation.

\section{Discussion}

More than half the cases of PA dilatation are associated with congenital heart diseases mainly in cases with the left-right shunt, due to volume and pressure overload in the right cardiac system which causes hemodynamic stress on the vessel wall. ${ }^{1}$. Congenital PS has also been associated with PA dilation. The mechanism of dilatation in PS is believed to be due to the jet of blood generated by the stenotic valve against the PA wall, without necessary relationship between the degree of stenosis and the degree of enlargement ${ }^{2}$. This condition can cause compression of nearby structures including the LMCA. We present the case of a patient with PS angina secondary to LMCA by the RPA. A relationship between PA diameter and 
LMCA compression was determined in a study with 36 patients with pulmonary dilation and pulmonary hypertension $(\mathrm{PH})$ of which 26 had angina. Compression was not seen in patients with pulmonary diameters $<40 \mathrm{~mm}$ and in patients with PA diameter $\geq 40 \mathrm{~mm}, 37 \%$ had compression of the LMCA ${ }^{3}$.

The best treatment option for patients with PA dilatation is uncertain. There are no clear guideline indications for surgical intervention but some authors recommend surgical intervention when the PA diameter is $\geq 5.5 \mathrm{~cm}$, if the diameter increases $\geq 0.5 \mathrm{~cm}$ in 6 months, compression of nearby structures occurs, thrombus formation in the aneurysm, presence of clinical symptoms, evidence of valvular pathologies or shunt, and if it presents signs of rupture or dissection'. In this case, the patient already had surgical indication for pulmonary valve replacement and due to the compression of the LMCA and presence of symptoms; he was also considered a candidate for RPA plasty, which was compressing the LMCA.

Surgical repair options for patients with PA dilatation include interposition of Dacron prosthesis or a homograft, reconstruction with pericardial patch or arterioplasty ${ }^{4}$. Our patient underwent pulmonary valve replacement, coronary bypass, PA and RPA plasty which was considered a high-risk surgery due to the procedure its self, the presence of biventricular dysfunction and the fact that it was his third cardiac surgery. All this combined eventually led to a bad outcome.

\section{Conclusions}

PA dilatation can cause compression of nearby structures, causing angina when it compresses the LMCA. There is an association between PS and PA dilatation being the jet of blood generated by the stenotic valve the pressumed cause. There is no clear consensus on the indications for surgical repair of PA dilatation although the presence of symptoms due to compression of other structures, like in the case presented, is generally considered an indication for intervention.

\section{Conflicts of interest}

None.

\section{Funding}

None.

\section{Ethical disclosures}

Protection of human and animal subjects. The authors declare that no experiments were performed on humans or animals for this study.

Confidentiality of data. The authors declare that no patient data appear in this article.

Right to privacy and informed consent. The authors have obtained the written informed consent of the patients or subjects mentioned in the article. The corresponding author is in possession of this document.

\section{References}

1. Kreibich M, Siepe M, Kroll J, Höhn R, Grohmann J, Beyersdorf F, et al. Aneurysms of the pulmonary artery. Circulation. 2015;131:310-6.

2. Van Buchem FS. Dilatation of the pulmonary artery in pulmonary stenosis. Circulation. 1956;13:719-24.

3. Mesquita SM, Castro CR, Ikari NM, Oliveira SA, Lopes AA. Likelihood of left main coronary artery compression based on pulmonary trunk diameter in patients with pulmonary hypertension. Am J Med. 2004;116:369-74.

4. Nair KS, Cobanoglu AM. Idiopathic main pulmonary artery. Ann Thorac Surg. 2001;71:1688-90. 